$551.513 .1: 551.515 .11$

\title{
Energy Cycle in the Lower Atmosphere
}

\author{
By Takio Murakami and Kiichi Tomatsu \\ Meteorological Research Institute, Tokyo \\ (Manuscript received 9 November 1964, in revised form 19 February 1965)
}

\begin{abstract}
After resolving the contour heights at the 500 and $1000 \mathrm{mb}$ levels into Fourier series, daily estimates have been made for all possible interaction terms, including the upward transfer of energy into the upper atmosphere, during a one year period from October 1962 to September 1963. It was found that (1) the release of available potential energy is maximum for the wave of wave number 3 in the lower atmosphere, presumably this conversion process is related to the diabatic effect due to the land and sea distribution, (2) the release of available potential energy is almost compensated for by the export of energy to the upper atmosphere, which is largely accomplished by the ultra-long waves of wave numbers 2 and 3, (3) the kinetic energy of the ultra-long waves is partly supplied from all the other waves through nonlinear interaction.

An examination of the monthly mean values of the interaction terms in January and February 1963, when the pronounced "blocking" persisted over the northern hemisphere, revealed that "blocking" plays an important part in maintaining the general circulation of the atmosphere. In section 5 will be presented the power spectrum of each interaction term, in order to study the nature of the fluctuations in the energy cycle of the atmosphere.
\end{abstract}

\section{Introduction}

By using the equations of motion derived by a scale analysis for spherical coordinates, we will first write down the energy equations in the wave domain of the Fourier series. These equations are essentially the same as those obtained by Saltzman (1957). When we apply the energy equations to the lower atmosphere which extends from $p=$ $1000 \mathrm{mb}$ up to $p=500 \mathrm{mb}$, we will obtain six interaction terms, each expressing the transformation of energy from one form to another. Some of the interaction terms have already been measured by Saltzman and Fleisher $(1960 \mathrm{a}, \mathrm{b}, \mathrm{c})$, these are the interaction between the zonal mean motion and the wave of wave number $n$, and the redistribution of kinetic energy, due to nonlinear interaction, between the wave of given wave number $n$ and all the other waves. In this paper we are going to evaluate all of the interaction terms in the domain of the Fourier series, in an effort to find the processes whereby the energy balance of the disturbance with a given wave number is achieved in the atmosphere.

Special attention will be paid to the following problems :

(1) What wave plays an important part in transferring kinetic energy, generated in the lower atmosphere through the baroclinic process of the ascending of warm air and the descending of cold air, to the upper atmosphere where the release of potential energy is supposed to be small? We will show in this paper that the generation of kinetic energy is accomplished, to a great extent, by the ultra-long waves of wave numbers 2 and 3 , in the winter season in particular, and the excess of kinetic energy for these waves is exported to the upper atmosphere to maintain the large-scale motion there. That is to say, the ultra-long waves appear to be more important than the long waves of wave number around 6 , the latter waves have long been known as unstable since the discussion by Charney (1947).

(2) How does each interaction term change with respect to time in its magnitude and sign? To study this, we shall first draw the time isopleths of the monthly mean values 
of the interaction terms, and next try to make the spectrum analysis, based upon the daily values of the interaction terms. There seems to be no doubt that such an analysis may serve to expose some of the interesting aspects of the general circulation.

\section{Equations in the domain of wave number}

Referring to the scale analysis made by one of the authors (1963), we shall use the vorticity and thermodynamic equations in spherical coordinates of the following form:

$$
\begin{aligned}
& \frac{\partial V^{2} \psi}{\partial t}+J V=f \frac{\partial \omega}{\partial p} \\
& \frac{\partial}{\partial t} \frac{\partial \phi}{\partial p}+J T=-\frac{\sigma}{f} \omega
\end{aligned}
$$

where

$$
\begin{aligned}
& J V=u \frac{\partial V^{2} \psi}{a \cos \varphi \partial \lambda}+v \frac{\partial V^{2} \phi}{a \partial \varphi}+\beta v \\
& J T=\left(u \frac{\partial}{a \cos \varphi \partial \lambda}+v \frac{\partial}{a \partial \varphi}\right) \frac{\partial \phi}{\partial p}
\end{aligned}
$$

In the above equations $\phi$ denotes the streamfunction, $\omega$ the vertical velocity, $\sigma$ the measure of the static stability assumed to be a function of pressure alone, and $a$ the radius of the earth ; $\phi$ is measured by $\phi / f$ where $\phi$ represents the isobaric height and $f$ is treated as constant as was shown by Murakami (1963). The eastward and northward components of the wind, $u$ and $v$, may be expressed by

$$
u=-\frac{\partial \psi}{a \partial \varphi}, \quad v=\frac{\partial \phi}{a \cos \varphi \partial \lambda}
$$

This geostrophic wind satisfies the following continuity equation

$$
\frac{\partial u}{a \cos \varphi \partial \lambda}+\frac{\partial v \cos \varphi}{a \cos \varphi \partial \varphi}=0
$$

where $\cos \varphi$ is regarded as a function of latitude $\varphi$.

Since the data available at the present study are only for the 500 and $1000 \mathrm{mb}$ levels, we are going to apply the vorticity equation (2.1) to the two reference levels just mentioned, and the thermodynamic equation (2.2) to the intermediate level $p=750$ mb. When we introduce finite differences for the vertical derivative in the vorticity equation, we first assume that the $500 \mathrm{mb}$ isobaric level is non-divergent, i.e., at this level $(\partial \omega / \partial p)$ is always equal to zero, and next assume that at the lowest levlel, $p=$ $1000 \mathrm{mb}$, the vertical velocity vanishes and thus the divergence $(\partial \omega / \partial p)$ is approximated by $-\left(4 \omega^{\mathrm{I}} / p_{0}\right)$ where $\omega \mathrm{II}$ denotes the vertica? velocity at the intermediate level $p=750 \mathrm{mb}$. Accordingly, we obtain

$$
\begin{aligned}
& \frac{\partial V^{2} \psi^{\mathrm{I}}}{\partial t}+J V^{\mathrm{I}}=0 \\
& \frac{\partial V^{2} \psi^{\mathrm{II}}}{\partial t}+J V^{\mathrm{II}}=-\frac{4 f}{P_{0}} \omega^{\mathrm{II}} \\
& \frac{\partial}{\partial t}\left(\phi-{ }^{\mathrm{II}} \psi^{\mathrm{I}}\right)+\frac{P_{0}}{2} J^{\mathrm{II}}=-\frac{\sigma P_{0}}{2 f} \omega^{\mathrm{II}}
\end{aligned}
$$

where the superscripts I, II and III refer to the quantities at the 500,750 , and $1000 \mathrm{mb}$ levels respectively; $P_{0}$ denotes the surface pressure $p=1000 \mathrm{mb}$.

Eliminating the first terms on the left of (2.7)-(2.9), we will obtain the diagnostic equation to determine the vertical velocity at the $750 \mathrm{mb}$ level as follows:

$$
\nabla^{2} \omega^{\mathrm{I}}-\frac{8 f^{2}}{\sigma P_{0}{ }^{2}} \omega^{\mathrm{I}}=\frac{f}{\sigma}\left[\frac{2}{P_{0}}\left(J V^{\mathrm{II}}-J V^{\mathrm{I}}\right)-\nabla^{2} J T^{\mathrm{II}}\right]
$$

We now expand the quantities appeared in (2.7)-(2.10) into the Fourier's series as follows :

$$
\begin{aligned}
& \psi^{L}=A_{0}{ }^{L}+\sum_{n=1}^{\infty}\left(A_{n}{ }^{L} \cos n \lambda+B_{n}{ }^{L} \sin n \lambda\right) \\
& J V^{L}=J V_{0}{ }^{L}+\sum_{n=1}^{\infty}\left(J V 1_{n}{ }^{L} \cos n \lambda+J V 2_{n}{ }^{L} \sin n \lambda\right) \\
& L=1,3 \\
& J T^{\mathrm{I}}=J T_{0}{ }^{\mathrm{II}}+\sum_{n=1}^{\infty}\left(J T 1_{n}{ }^{\mathrm{II}} \cos n \lambda+J T 2_{n}{ }^{\mathrm{II}} \sin n \lambda\right) \\
& \omega^{\mathrm{I}}=W_{0}{ }^{\mathrm{II}}+\sum_{n=1}^{\infty}\left(W_{n}{ }^{\mathrm{II}} \cos n \lambda+\Omega_{n}{ }^{\mathrm{I}} \sin n \lambda\right)
\end{aligned}
$$

When the expression (2.11) is substituted into (2.7)-(2.10) and we equate the coefficients of the sin-terms and cos-terms respectively, we will obtain the following equations: 


$$
\begin{aligned}
& \frac{\partial V^{2} A_{n} \mathrm{I}}{\partial t}=-J V 1_{n}{ }^{\mathrm{I}} \\
& \frac{\partial V^{2} B_{n}{ }^{\mathrm{I}}}{\partial t}=-J V 2_{n}{ }^{\mathrm{I}} \\
& \frac{\partial V^{2} A_{n} \text { III }}{\partial t}=-J V 1_{n}{ }^{\mathrm{III}}-\frac{4 f}{P_{0}} W_{n}{ }^{\mathrm{II}} \\
& \frac{\partial V^{2} B_{n} \mathrm{III}}{\partial t}=-J V 2_{n} \mathrm{II}-\frac{4 f}{P_{0}^{-}} \Omega_{n} \mathrm{II} \\
& \frac{\partial}{\partial t}\left(A_{n} \mathrm{II}-A_{n} \mathrm{I}\right)=-\frac{P_{0}}{2} J T 1_{n} \mathrm{I}-\frac{\sigma P_{0}}{2 f} W_{n}^{\mathrm{II}} \\
& \frac{\partial}{\partial t}\left(B_{n} \mathrm{III}-B_{n} \mathrm{I}\right)=-\frac{P_{0}}{2} J T 2_{n}{ }^{\mathrm{I}}-\frac{\sigma P_{0}}{2 f} \Omega_{n} \mathrm{II} \\
& \nabla^{2} W_{n} \mathrm{II}-\frac{8 f^{2}}{\sigma P_{0}{ }^{2}} W_{n} \text { II } \\
& =\frac{f}{\sigma}\left[\frac{2}{P_{0}}\left(J V 1_{n}{ }^{\mathrm{BI}}-J V 1_{n}{ }^{\mathrm{I}}\right)-\nabla^{2} J T 1_{n} \mathrm{II}\right] \\
& \nabla^{2} \Omega_{n} \mathrm{II}-\frac{8 f^{2}}{\sigma P_{0}^{2}} \Omega_{n} \mathrm{II} \\
& =\frac{f}{\sigma}\left[\frac{2}{P_{0}}\left(J V 2_{n} \mathrm{II}-J V 2_{n}{ }^{\mathrm{I}}\right)-\nabla^{2} J T 2_{n} \mathrm{I}\right]
\end{aligned}
$$

In the above equations, the Laplacian $\nabla^{2}$ is expressed by

$$
\nabla^{2}=\frac{1}{a^{2}}\left[-\frac{n^{2}}{\cos ^{2} \varphi}-\tan \varphi \frac{\partial}{\partial \varphi}+\frac{\partial^{2}}{\partial \varphi^{2}}\right]
$$

Likewise we will obtain for the zonal motion $(n=0)$ the following set of equations

$$
\begin{aligned}
& \frac{\partial V^{2} A_{0} \mathrm{I}}{\partial t}=-J V_{0}^{\mathrm{I}} \\
& \frac{\partial V^{2} A_{0}^{\mathrm{III}}}{\partial t}=-J V_{0} \mathrm{III}-\frac{4 f}{P_{0}} W_{0} \mathrm{II} \\
& \frac{\partial}{\partial t}\left(A_{0} \mathrm{II}-A_{0} \mathrm{I}\right)=-\frac{P_{0}}{2} J T_{0} \mathrm{II}-\frac{\sigma P_{0}}{2 f} W_{0} \mathrm{II} \\
& \nabla^{2} W_{0} \mathrm{II}-\frac{8 f^{2}}{\sigma P_{0}^{2}} W_{0} \mathrm{II} \\
& \quad=\frac{f}{\sigma}\left[\frac{2}{P_{0}}\left(J V_{0} \mathrm{II}-J V_{0} \mathrm{I}\right)-\nabla^{2} J T_{0} \mathrm{II}\right]
\end{aligned}
$$

We shall now consider what the systems of equations (2.12)-(2.17) and (2.21)-(2.23) imply about the energetics. Multiplying both sides of $(2.12)$ by $\left(-A_{n} \mathrm{I}\right),(2.13)$ by $\left(-B_{n} \mathrm{I}\right)$,
(2.14) by $\left(-A_{n}\right.$ III $)$ and (2.15) by $\left(-B_{n}\right.$ III respectively, adding up the resulting equations thus obtained, followed by an integration with respect to latitude, we will obtain the kinetic energy equation for the wave with wave number $n$. The equation expressing the rate of change of available potential energy may be obtained after multiplying both sides of (2.16) by $\left(A_{n}\right.$ III $\left.-A_{n} \mathrm{I}\right)$ and (2.17) by $\left(B_{n} \mathrm{II}-B_{n}{ }^{\mathrm{I}}\right)$, adding up the resulting equations obtained, and integrating with respect to latitude. The results are

$$
\begin{aligned}
& \frac{\partial K(n)}{\partial t}=M(n)+L(n)+N(n)+C(n) \\
& \frac{\partial P(n)}{\partial t}=S(n)+T(n)-C(n)
\end{aligned}
$$

where

$$
\begin{aligned}
& K(n)=\frac{\pi P_{0}}{8 g} \sum_{L=1}^{2} \int\left[\frac{n^{2}}{\cos \varphi}\left\{\left(A_{n}{ }^{2 L-1}\right)^{2}+\left(B_{n}{ }^{2 L-1}\right)^{2}\right\}\right. \\
& \left.\quad+\cos \varphi\left\{\left(\frac{\partial A_{n}{ }^{2 L-1}}{\partial \varphi}\right)^{2}+\left(\frac{\partial B_{n}{ }^{2 L-1}}{\partial \varphi}\right)^{2}\right\}\right] d \varphi \quad
\end{aligned}
$$

$P(n)=\frac{\pi a^{2} f^{2}}{g \sigma P_{0}} \int\left[\left(A_{n} \mathrm{III}-A_{n}{ }^{\mathrm{I}}\right)^{2}+\left(B_{n} \mathrm{III}-B_{n} \mathrm{I}\right)^{2}\right]$

$\times \cos \varphi d \varphi$

$$
\begin{aligned}
& M(n)=-\frac{\pi P_{0}}{4 g a^{2}} \sum_{L=1}^{2} \int n \frac{\partial A_{0}{ }^{2 L-1}}{\partial \varphi} \frac{\partial}{\cos \varphi \partial \varphi} \\
& \quad \times\left[\left(A_{n}{ }^{2 L-1} \frac{\partial B_{n}{ }^{2 L-1}}{\partial \varphi}-B_{n}{ }^{2 L-1} \frac{\partial A_{n}{ }^{2 L-1}}{\partial \varphi}\right) \cos \varphi\right] d \varphi
\end{aligned}
$$

$$
\begin{aligned}
& L(n)=\frac{\pi a^{2} P_{0}}{4 g} \sum_{L=1}^{2} \int\left[A_{n}{ }^{2 L-1} J V 1_{n}{ }^{2 L-1}\right. \\
& \left.\quad+B_{n}{ }^{2 L-1} J V 2_{n}{ }^{2 L-1}\right] \cos \varphi d \varphi-M(n)
\end{aligned}
$$

$N(n)=\frac{\pi a^{2} f}{g} \int\left[W_{n}{ }^{\pi} A_{n}{ }^{\mathrm{T}}+\Omega_{n}{ }^{\mathrm{I}} B_{n}^{\mathrm{I}}\right] \cos \varphi d \varphi$

* If we multiply both sides of the original equation $(2.1)$ by $(-\phi)$, integrate from the lower level $p=1000 \mathrm{mb}$ to the upper level $p=500 \mathrm{mb}$, we will obtain

$N^{\prime}(n)=\frac{\pi a^{2} f}{g} \int\left[W_{n} \mathrm{I} A_{n}^{\mathrm{I}}+\Omega_{n}{ }^{\mathrm{I}} B_{n} \mathrm{I}\right] \cos \varphi d \varphi$

This term $N^{\prime}(n)$ corresponds to $N(n)$ in (2.31), and depends upon the correlation between the vertical velocity at the $500 \mathrm{mb}$ level and the isobaric height at the same level. 


$$
\begin{aligned}
& C(n)= \frac{\pi a^{2} f}{g} \int\left[W_{n} \mathrm{II}\left(A_{n} \mathrm{III}-A_{n}^{\mathrm{I}}\right)\right. \\
&\left.+\Omega_{n} \mathrm{II}\left(B_{n} \mathrm{III}-B_{n} \mathrm{I}\right)\right] \cos \varphi d \varphi \\
& S(n)= \frac{2 \pi f^{2}}{g \sigma P_{0}} \int n \frac{\partial A_{0} \mathrm{III}-A_{0} \mathrm{I}}{\partial \varphi} \\
& \times\left[A_{n}^{\mathrm{I}} B_{n}^{\mathrm{III}}-A_{n}{ }^{\mathrm{III}} B_{n}^{\mathrm{I}}\right] d \varphi \\
& T(n)=-\frac{\pi a^{2} f^{2}}{g \sigma} \int\left[\left(A_{n} \mathrm{II}-A_{n}^{\mathrm{I}}\right) J T 1_{n} \mathrm{II}\right. \\
&\left.+\left(B_{n} \mathrm{II}-B_{n}^{\mathrm{I}}\right) J T 2_{n} \mathrm{II}\right] \cos \varphi d \varphi-S(n)
\end{aligned}
$$

Likewise, we will obtain from (2.21)-(2.23) the energy equations for the zonal motion as follows :

$$
\begin{aligned}
& \frac{\partial K(0)}{\partial t}=M(0)+N(0)+C(0) \\
& \frac{\partial P(0)}{\partial t}=S(0)-C(0)
\end{aligned}
$$

where

$$
\begin{aligned}
& K(0)=\frac{\pi P_{0}}{4 g} \sum_{L=1}^{2} \int\left(\frac{\partial A_{0}^{2 L-1}}{\partial \varphi}\right)^{2} \cos \varphi d \varphi \\
& P(0)=\frac{2 \pi a^{2} f^{2}}{g \sigma P_{0}} \int\left(A_{0} \mathrm{II}-A_{0}{ }^{\mathrm{I}}\right)^{2} \cos \varphi d \varphi \\
& M(0)=-\sum_{n=1}^{\infty} M(n) \\
& N(0)=\frac{2 \pi a^{2} f}{g} \int W_{0} \mathrm{I} A_{0}^{\mathrm{I}} \cos \varphi d \varphi \\
& C(0)=\frac{2 \pi a^{2} f}{g} \int W_{0} \mathrm{I}\left(A_{0} \mathrm{II}-A_{0} \mathrm{I}\right) \cos \varphi d \varphi \\
& S(0)=-\sum_{n=1}^{\infty} S(n)
\end{aligned}
$$

We may regard $M(n)$ as expressing the interaction between the zonal mean flow and a disturbance with a wave number $n, L(n)$, which vanishes when summed over all wave numbers, as indicating a transformation of kinetic energy, due to nonlinear interaction, between a disturbance of a given wave number $n$ and disturbances of all other wave numbers. A comparison between (2.31) and (2.31)' will reveal that $N(n)$ gives information about a transfer of energy across the uppermost level $p=500 \mathrm{mb}$. In equations (2.25) and (2.26), $C(n)$ appears twice with opposite sign, indicating that this term represents a conversion between available potential and kinetic energy associated with a disturbance of wave number $n$. $S(n)$ may be interpreted as a measure of the redistribution of available potential energy between the zonal mean flow and a disturbance of wave number $n$, and $T(n)$, which vanishes when summed over all wave numbers, as indicating a transformation of available potential energy between a disturbance of a given wave number $n$ and disturbances of all other wave numbers. Furthermore, it is clear that (1) $M(o)$ represents the interaction of kinetic energy between the zonal motion and disturbances of all wave numbers, (2) $N(o)$ an upward flux of energy due to the mean meridional cell $W_{0},(3) C(o)$ the conversion between $P(o)$ and $K(o)$, and (4) $S(o)$ the redistribution of available potential energy between the zonal motion and disturbances of all wave numbers.

\section{Data and procedure}

The present study covers the one year period from October 1962 to September 1963, incl. We used in this study the data from the two isobaric levels of 500 and $1000 \mathrm{mb}$ at the standard time 12 GMT. The isobaric heights were read from the analysed maps at every 10 degree of latitude from $20^{\circ} \mathrm{N}$ to $80^{\circ} \mathrm{N}$ and at every 10 degree of longitude, these were prepared at the Long-Range Weather Forecasting Section of the Japan Meteorological Agency. In order to make the computations followed easier, however, the isobaric heights at every 5 degree of latitude were interpolated by harmonic analysis at respective longitudes.

Using the gridpoint values of the isobaric height, we measured at first the daily values of the horizontal advections of vorticity, $J V$, and of thickness, $J T$, at respective gridpoints. We are now ready to evaluate the Fourier components (from $n=0$ up to $n=10$ ) of $\phi, J V$ and $J T$ by using (2.11). Introducing the finite differences for Laplacian on (2.18) and (2.19), we will obtain the sets of linear algebraic equations, not reproduced here, to find the latitudinal distribution of $W_{n}$ II and $\Omega_{n}$ II In deriving these algebraic equations we have assumed that any component of the vertical 
velocity vanishes at $25^{\circ} \mathrm{N}$ and at $75^{\circ} \mathrm{N} ; W_{n}$ II and $\Omega_{n}$ II were estimated at every 5 degree of latitude from $30^{\circ} \mathrm{N}$ to $70^{\circ} \mathrm{N}$.

When integrating (2.27)-(2.34) and (2.37) -(2.42) with respect to latitude, we have considered the domain extending from $30^{\circ} \mathrm{N}$ to $70^{\circ} \mathrm{N}$. We must assume that the region we treat is large enough to represent the interactions over the whole northern hemisphere.

\section{The interàction terms}

A brief discussion of the results obtained for several statistical quantities will be given in this section. We shall first demonstrate the geographical distribution of $J T$ II in Fig. 1. By means of the continuity equation (2.6), JTII may be expressed as

$J T^{\mathrm{I}}=\frac{1}{a \cos \varphi}\left[\frac{\partial}{\partial \lambda}\left(u \frac{\partial \psi}{\partial p}\right)+\frac{\partial}{\partial \varphi}\left(v \frac{\partial \psi}{\partial p} \cos \varphi\right)\right]_{p=750}$

Accordingly $J T^{\mathrm{II}}$ may be interpreted as indicating the horizontal divergence (convergence) of sensible heat flux; a minus sign represents a divergence of sensible heat flux and a positive sign, a convergence of sensible heat flux. In Fig. 1a is presented the distri-

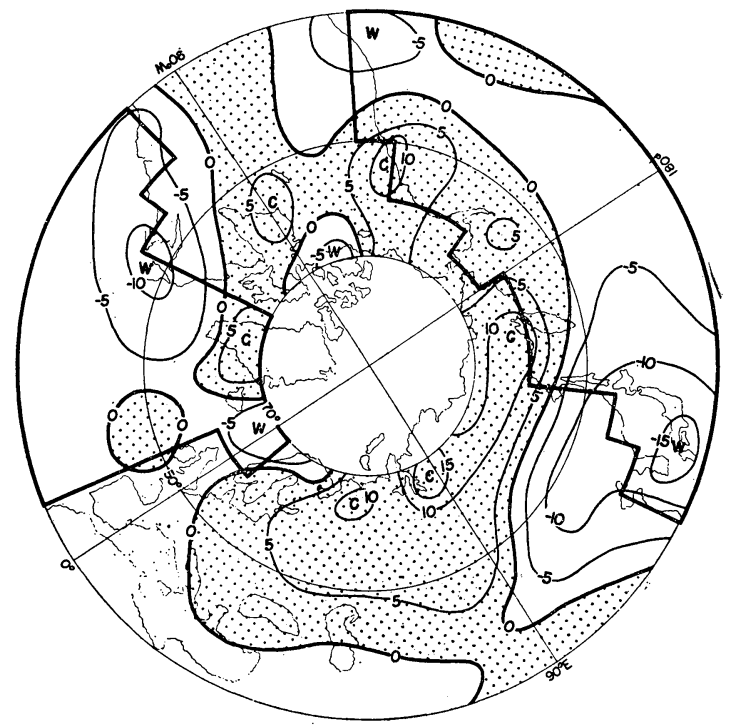

Fig. 1a. The winter half-year mean of $J T \mathbb{1}$, obtained by (4.1), from 1 October 1962 to 31 March 1963, in the unit of $10^{-2} \mathrm{~m}^{2} \mathrm{mb}^{-1}$ $\mathrm{sec}^{-2}$. The isolines are drawn at $5 \times 10^{-2}$ $\mathrm{m}^{2} \mathrm{mb}^{-1} \mathrm{sec}^{-2}$ intervals.

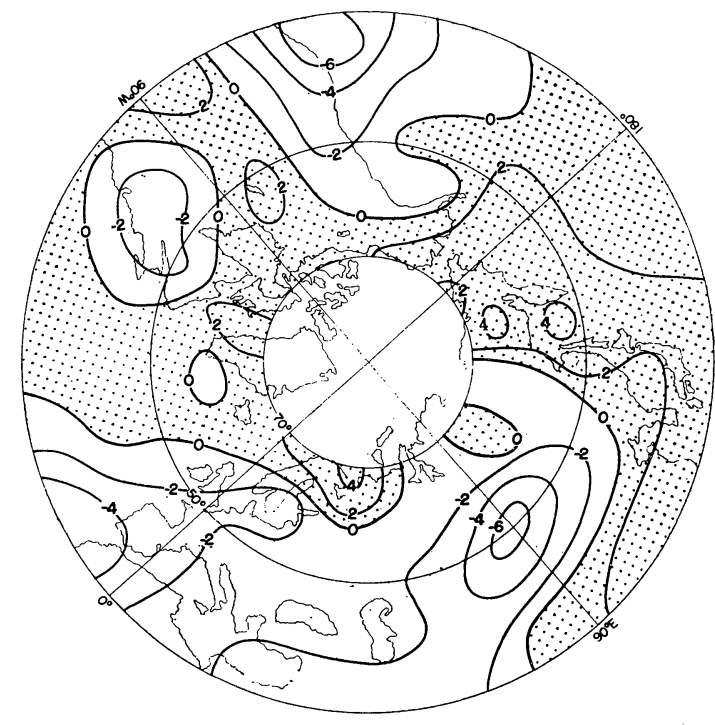

Fig. 1b. The summer half-year mean of JTII for the period from 1 April to 30 September 1963. The isolines are for $2 \times 10^{-2} \mathrm{~m}^{2}$ $\mathrm{mb}^{-1} \mathrm{sec}^{2}$ intervals.

bution of the winter half-year mean of $J T^{\mathrm{II}}$. We encounter large negative values exceeding $-10 \times 10^{-2} \mathrm{~m}^{2} \mathrm{sec}^{-2} \mathrm{mb}^{-1}$ near Japan and the eastern border of the North American continent, these are the locations where we expect a great deal of heat supply from the sea surface in the winter season. The value $-10^{-1} \mathrm{~m}^{2} \mathrm{sec}^{-2} \mathrm{mb}^{-1}$ corresponds to about $+2.4^{\circ} \mathrm{C}$ /day in the familiar unit. We also note in Fig. $1 \mathrm{a}$ that $J T^{\mathrm{II}}$ is generally negative over the oceans and positive over the continents. The space mean values of $J T^{\mathrm{II}}$ over the Pacific and the Atlantic, enclosed by the full lines in Fig. $1 \mathrm{a}$, are found to be $+0.49^{\circ} \mathrm{C} /$ day and $+0.59^{\circ} \mathrm{C}$ respectively; there is no significant difference between the two values. Likewise we estimated the space mean values over the continents; the results are $-0.49^{\circ} \mathrm{C} /$ day over the Eurasian continent and $-0.22^{\circ} \mathrm{C} /$ day over the North American continent. From this, it may be guessed that in the winter the diabatic cooling at the ground surface of the Eurasian continent is about twice as large as that over the North American continent.

Another thing to be noted in Fig. $1 \mathrm{a}$ is that $J T^{\mathrm{II}}$ is generally negative in the southern latitudes and mostly positive in the northern latitudes. The zonal mean of $J T^{\text {II }}$ 
(i.e., $J T_{0} \mathrm{I}$ ) is minimum at $40^{\circ} \mathrm{N}$, amounting to $+0.7^{\circ} \mathrm{C}$ /day in the familiar unit, and is maximum at $65^{\circ} \mathrm{N}$ with its corresponding value $-1.1^{\circ} \mathrm{C} /$ day. Such distribution of $J T_{0}$ II may contribute to generate the indirect circulation cell for the zonal mean vertical velocity, as will be seen in (2.24). Actual computation of (2.24) for the winter halfyear reveals that there is downward motion in the south with its maximum at $40^{\circ} \mathrm{N}$ amounting to $4 \times 10^{-5} \mathrm{mb} \mathrm{sec}^{-1}\left(0.04 \mathrm{~cm} \mathrm{sec}^{-1}\right)$ and upward motion in the north, reaching $0.06 \mathrm{~cm} \mathrm{sec}-1$ at $60^{\circ} \mathrm{N}$.

Fig. $1 \mathrm{~b}$ illustrates the geographical distribution of $J T^{\text {II }}$ in the summer half-year. The pattern is almost opposite to that in the winter half-year, i.e., a negative value prevails over the continents and a positive value over the oceans. Perhaps such distribution results from the expected contribution of
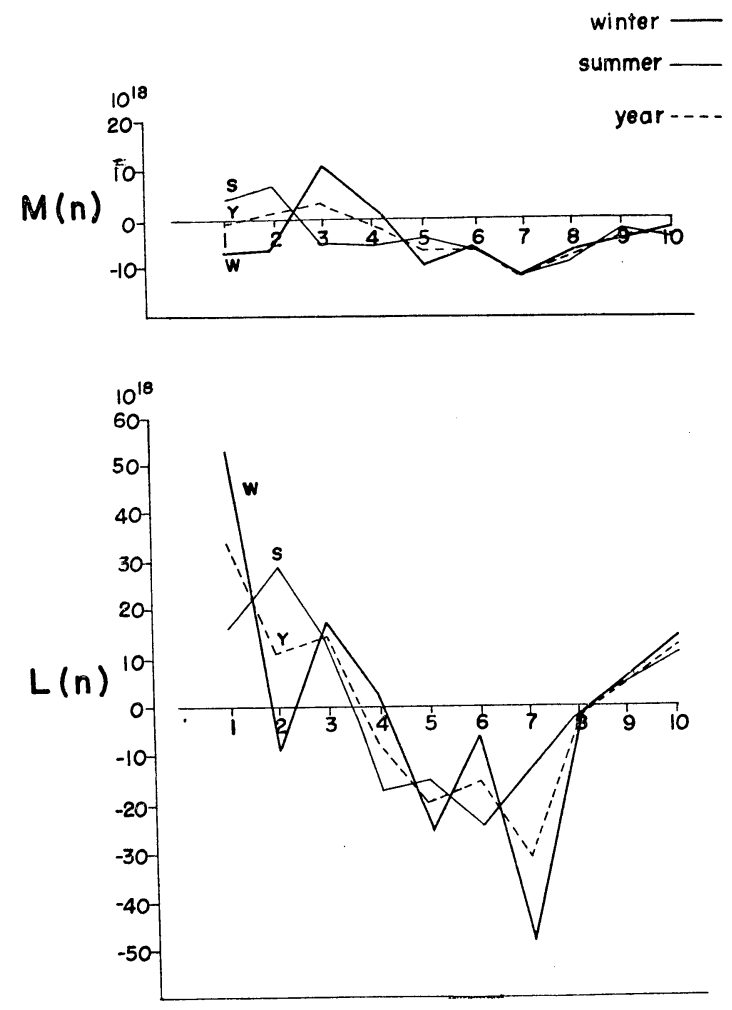

Fig. 2a. $M(n)$ (top) and $L(n)$ (bottom) as a function of wave number. The unit is $10^{18}$ ergs $\mathrm{sec}^{-1}$. The winter half-year mean is drawn by the heavy full line, the summer half-year mean by the thin full line, and the yearly mean by the dotted line. non-adiabatic heating at the earth's surface; in the summer the continents act as heat sources and the oceans as sinks. The space mean value of $J T^{\text {II }}$ over the Eurasian continent is estimated to be $+0.27^{\circ} \mathrm{C} /$ day.

Having discussed so far the distribution of $J T^{\text {II }}$ in (2.9), we now move on to the discussions concerning the interaction terms shown in (2.25), (2.26), (2.35) and (2.36). The dependency of the time mean values of respective interaction terms upon the wave number is presented in Fig. 2.

The yearly mean of $M(n)$ is negative for almost all wave numbers, except for $n=2$ and 3, which is in qualitative agreement with the results obtained by Saltzman and Fleisher (1960 a). A negative sign indicates the kinetic energy transfer from $K(n)$ into $K(o)$. Of course, the net transfer, i.e., the sum over the ten wave numbers, is directed from the
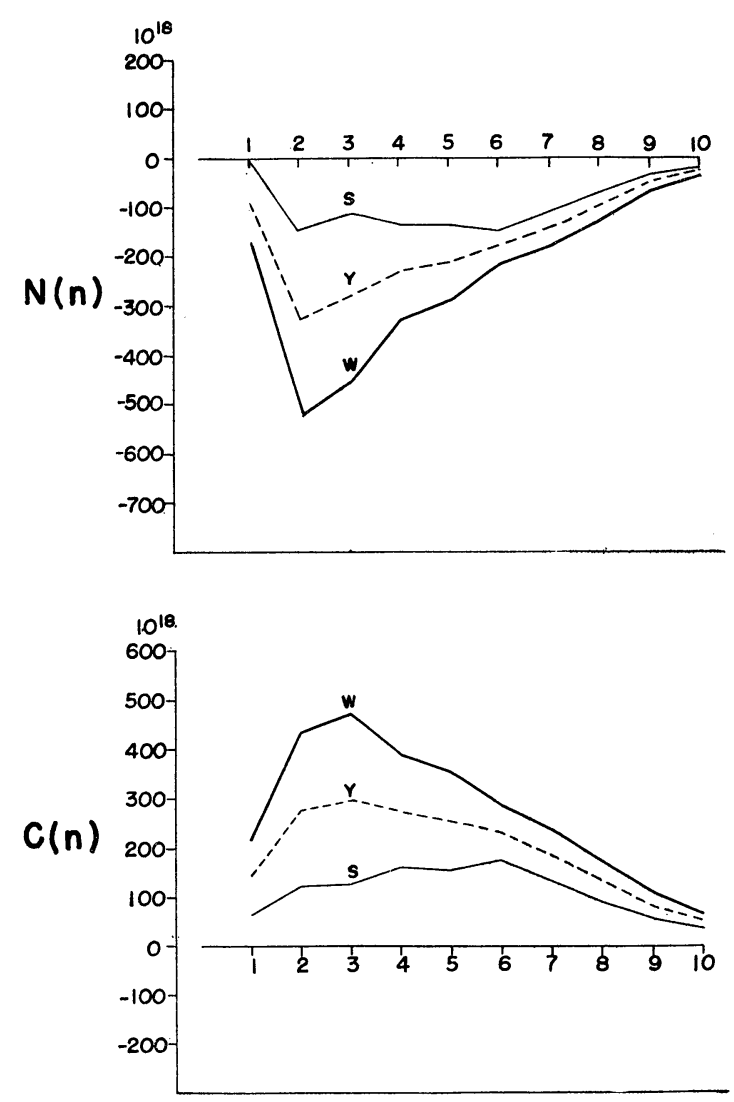

Fig. 2b. $\quad N(n)$ (top) and $C(n)$ (bottom) as a function of wave number. Refer to Fig. 2a for further explanations. 

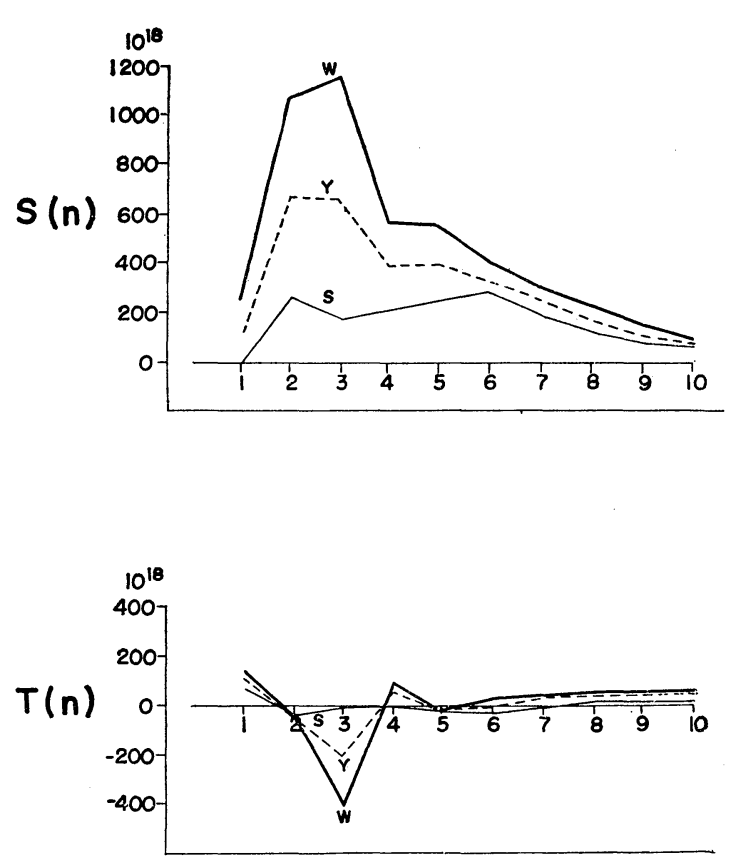

Fig. 2c. $S(n)$ (top) and $T(n)$ (bottom) as a function of wave number. See Fig. 2a for further explanations.

eddies to the zonal flow.

As shown in (2.30), the sign of $L(n)$ is defined so that a negative sign indicates a loss of kinetic energy of the wave of given wave number $n$, through nonlinear interaction with all other waves, and a positive sign, a gain of kinetic energy. It is of interest to find in Fig. $2 \mathrm{a}$ that the waves of wave numbers 5 to 7 furnish their kinetic energy to both the ultra-long waves of $n=1$ to 3 and to the shorter waves of $n=9$ to 10 . This result agrees, in a qualitative sense, with the findings by Saltzman and Fleisher $(1960 \mathrm{~b})$. Another important thing we notice in Fig. $2 \mathrm{a}$ is that in the winter half-year $L(n)$ is also negative for $n=2$. It has been pointed out by Murakami (1960) that the stationary disturbances, which are largely composed of waves of wave numbers 2 to 3 , give their kinetic energy to the transient eddies, which are supposed to be associated primarily with the migratory troughs and wedges. Then we come to the problem as to what process is responsible for maintaining the kinetic energy of the ultra-long waves of wave numbers $n=2$ to 3 .
Of the most significance in Fig. $2 \mathrm{~b}$ is the fact that $N(n)$ is negative for all wave numbers with its minimum at $n=2$, reaching $-300 \times 10^{18}$ ergs $\mathrm{sec}^{-1}$ in the yearly mean. A minus sign expresses an export of energy from the lower to the upper atmosphere. It is, therefore, a tentative conclusion in this paper that there is a constant energy supply from the lower to the upper atmosphere, and the supply is accomplished to a great extent by the ultra-long waves of $n=2$ to 3 . This conclusion seems to be supported by the theoretical findings by Murakami (1964) that the conversion of potential energy into kinetic energy is extremely small in the upper atmosphere.

Figure 2b shows also that $C(n)$ is positive for all wave numbers, a positive sign representing a conversion of available potential energy into kinetic energy. It is more or less curious to find that in the winter halfyear $C(n)$ attains its maximum at the wave number 3 , amounting to about $500 \times 10^{18}$ ergs $\mathrm{sec}^{-1}$. In the summer half-year, however, $C(n)$ is largest for the wave number 6 , which is the wave number of the most unstable wave, as was pointed out by many authors (e.g. Phillips, 1954). Since the magnitude of $C(n)$ in the summer is considerably smaller than that in the winter, the maximum value of $C(n)$ in the entire year is again encountered at $n=3$. It is, here, of interest to compare the present result with the results obtained by Wiin-Nielsen (1959), and by Saltzman and Fleisher $(1960 \mathrm{c})$. Based upon the data from the 500 and $850 \mathrm{mb}$ levels, they found that the release of potential energy reaches a relative maximum when $n=3$ and attains the absolute maximum $n=6$.

It may not be easy to offer an explanation why we encountered the marked maximum of $C(n)$ for the wave number 3 , in the winter in particular. One might say that it would be due mainly to the diabatic effect, originated from the sensible heat supply at the earth's surface and determined to a great extent by the land and sea distributions, that the conversion of available potential energy into kinetic energy is most pronounced for the wave of wave number 3 ; this diabatic effect is supposed to be associated with the thermally forced development of the distur- 
bances in the atmosphere. As has long been known among meteorologists, on the other hand, pure baroclinic instability of the disturbances is most active for the wave number about 6 ; the wave with wave number around 6 would grow essentially at the expense of the potential energy. Only difference between our measurement and the measurements made by Wiin-Nielsen and by Saltzman and Fleisher, cited above, would be the data source from which the estimations have been made; whereas they used the two isobaric levels of 500 and $850 \mathrm{mb}$, we used the data from the 500 and $1000 \mathrm{mb}$ levels. It is to be expected that more diabatic effect due to sensible heat supply at the earth's surface is included in our data than those they used, because this diabatic heating is believed to decrease rather rapidly with increasing height. This would be of use in explaining why they found observationally that $C(n)$ reaches its maximum for the wave number 6 , whereas our results show the pronounced maximum at the wave number 3 in the winter season. In this regard we think we must be careful when comparing the different results from different sources of data.

Now let us take a look at Fig. $2 \mathrm{c}$, showing the dependency of the mean values of $S(n)$ upon wave number $n$. We have defined $S(n)$ in (2.33) so that a positive value signifies a transfer of available potential energy from $P(o)$ into $P(n)$. It at once appears in Fig. 2c that the transfer of available potential energy is exceedingly large for the ultra-long waves of $n=2$ and 3, particularly in the winter halfyear. As is seen in the expression (2.33), $S(n)$ is related to the sensible heat transfer due to the wave of wave number $n$. Quite recently Wiin-Nielsen, Brown and Drake (1963) showed from observations that the ultra-long waves of $n=2$ to 3 are most effective in transferring sensible heat northward. Accordingly we think it has been established by their study and by the present study that $S(n)$ is largest for the ultra-long waves of $n=2$ and 3. At present, however, there seems to be no satisfactory theory to explain this observational finding; according to the instability theories so far been made, the ultra-long waves are always stable and the waves of wave number around 6 is in most unstable state, and hence the largest transfer of available potential energy from $P(o)$ to $P(n)$ would be encountered for the most unstable wave $(n=6)$.

So far as the present authors know, no observational attempt has thus far been made to estimate $T(n)$, expressing the redistribution of available potential energy due to the nonlinear interaction. A positive sign of this term is defined to represent a gain of available potential energy associated with the wave of given wave number $n$ and a negative sign, a loss of it. A glance at Fig. $2 \mathrm{c}$ reveals that the wave of wave number 3 gives available potential energy to the rest of the waves considered. Since the available potential energy is related to the temperature contrast in the horizontal surface, it may be permissible to say that the wave of $n=3$ plays an important part in establishing the temperature pattern in the atmosphere.

We shall now summarize the energy balance of the wave of given wave number $n$ with the help of an energy flow diagram. Figure 3 is for the wave of $n=3$. The arrows with accompanying figures denote the directions and magnitudes of the average energy transfers for the entire year considered. No attempt has been made to compute the magnitude of the generation of eddy available potential energy $P(3)$. Only its direction has been assumed from the sum of $S(3), T(3)$ and $C(3)$.*

Glancing at Fig. 3, it appears at once that the two interaction terms of $M(3)$ and $L(3)$ are of one order of magnitude smaller than the other interaction terms. Both $M(3)$ and $L(3)$ relate to the triple correlation of the wind velocity. In the lower atmosphere with which we are now concerned, the wind

* Strictly speaking, the sum of $S(3), T(3)$ and $C(3)$ is not exactly equal to the generation of $P(3)$. We used in this study the most simplified model, i.e., the quasi-geostrophic model, in which (1) the static stability is assumed to be a function of pressure alone, (2) no vertical transfer of sensible heat is allowed, (3) no diabatic effect is considered when estimating the vertical velocity. Therefore the errors originated from the model are inevitably included in the estimated sum of $S(3)$, $T(3)$ and $C(3)$, in addition to the actual generation of $P(3)$. 


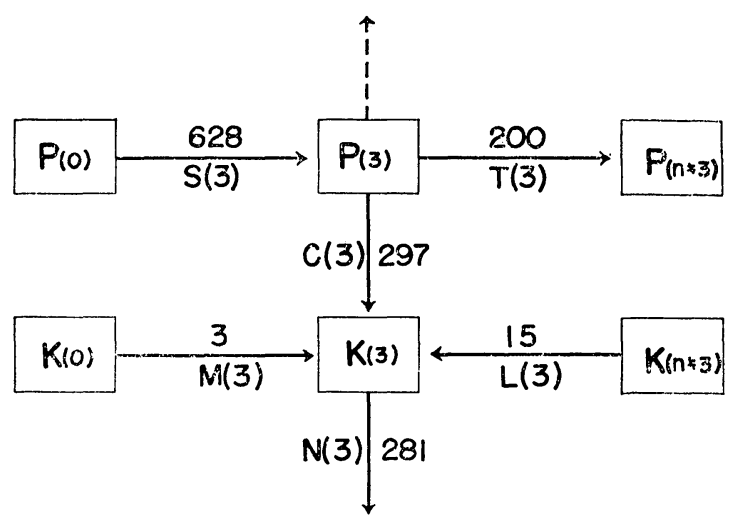

Fig. 3. A schematic picture showing the energy budget for the wave of wave number 3 . The unit of the interaction terms is $10^{18}$ ergs $\sec ^{-1}$.

velocity is so small that these interaction. terms are observed to be small. If heights up to the stratosphere were sampled, both $M(3)$ and $L(3)$ would become much larger. On the other hand, it is expected, not without reason, that the three interaction terms $S(3), T(3)$ and $C(3)$ are larger in the lower atmosphere and smaller in the upper atmosphere. Accordingly, if we extend our analysis throughout the entire atmosphere, the relative magnitude of each interaction term would be found to be quite different from what we observed in Fig. 3.

There is a large supply of potential energy through transfer from $P(o)$. This supply is slightly larger than the loss of available potential energy through transfer to the other waves, $T(3)$, and through conversion into kinetic energy, $C(3)$. From this it may be guessed that $P(3)$ dissipates due to the effect of non-adiabatic heating, this direction is shown by the dotted line. As can be seen in the diagram, it is most significant that the loss of $K(3)$ through transfer to the upper atmosphere, expressed by $N(3)$, is almost compensated for by the release of available potential energy, denoted by $C(3)$. In this regard, $N(3)$ and $C(3)$ are said to be primarily important processes in the energy balance of the wave of wave number 3 . It is also worthwhile to note in Fig. 3 that even though $L(3)$ is very small in its magnitude, $L(3)$ seems to be significant when we consider the kinetic energy budget of $K(3)$ in the lower atmosphere. There is a gain of $K(3)$ through the process of $C(3), L(3)$ and $M(3)$, totaling $315 \times 10^{18} \mathrm{ergs} \mathrm{sec}^{-1}$. There is also a steady loss of $K(3)$ through the process of $N(3)$, amounting to $281 \times 10^{18} \mathrm{ergs} \mathrm{sec}^{-1}$. The difference between gain and loss is $34 \times$ $10^{18}$ ergs $\mathrm{sec}^{-1}$, which is presumably equal to the frictional dissipation. Since the magnitude of $L(3)\left(15 \times 10^{18}\right.$ ergs $\left.\mathrm{sec}^{-1}\right)$ is of the same order as that of the net sum $\left(34 \times 10^{18}\right.$ ergs $\left.\mathrm{sec}^{-1}\right)$, we are led to conclude that the nonlinear interaction $L(3)$ is of importance when considering the maintenance of $K(3)$ in the lower atmosphere.

Let us now turn our attention to the energy cycle for the zonal mean motion. In Fig. 4 is presented the yearly mean values of the interaction terms appearing on (2.35) and (2.36). In this schematic picture $P^{\prime}$ denotes the eddy available potential energy obtained by summing up (2.28) from $n=1$ to $n=10$, and $K^{\prime}$ the eddy kinetic energy which refers to the sum of (2.27) over all wave numbers. The kinetic energy transfer from $K^{\prime}$ to $K(o)$ amounts to only about $40 \times 10^{18} \mathrm{ergs}^{\mathrm{sec}}{ }^{-1}$.

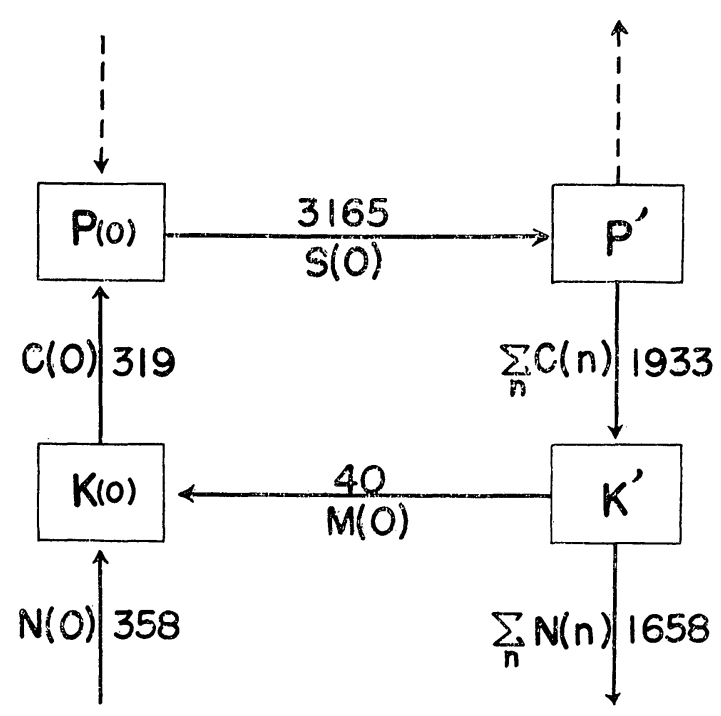

Fig. 4. A schematic picture showing the energy budget for the zonal mean motion and the eddies. $P^{\prime}$ represents the eddy available potential energy, obtained by summed over (2.28) from $n=1$ to $n=10$, and $K^{\prime}$ the eddy kinetic energy representing the sum of (2.27) for all wave numbers. The unit is $10^{18} \mathrm{ergs} \mathrm{sec}^{-1}$ for respective interaction terms. 
There is a large downward transport of geopotential due to the zonal mean vertical velocity $W_{0}$ II. As was pointed out before, $W_{0}$ II is downward in the southern latitudes where the geopotential is larger at the $500 \mathrm{mb}$ level, and is upward in the northern latitudes where the geopotential is smaller. This is why we find downward transport of the zonal mean geopotential in Fig. 4. Owing to the existence of the indirect circulation cell, it is a matter of course that there is energy conversion from $K(o)$ into $P(o)$. Because the loss of $P(o)$ through thansferring into $P^{\prime}$ is much larger than the gain of it through conversion from $K(o)$, there should be a large generation of $P(o)$ due to the nonadiabatic heating.

We shall now take look at the time isopleths of the monthly mean values of the interaction terms, these are presented in Fig. 5. Figure $5 \mathrm{a}$ demonstrates the isopleth of $M(n)$, and reveals that $M(n)$ is negative for the waves of wave numbers 5 to 8 throughout almost the entire year, the minimum being found around $n=7$. As for the ultralong waves, however, the sign of $M(n)$ appears to change significantly from month to month. We find extremely large positive values in January and February for the waves $n=2$ and 3 , indicating that there was a large transfer of kinetic energy from the zonal motion to the very long waves, i.e., these were in a barotropically unstable state. In January and February, 1963, the pronounced "blocking" persisted over the northern hemisphere. Figure 6 shows the anormaly pattern of the monthly mean $500 \mathrm{mb}$ heights in January and indicates that the marked "blocking" patterns, characterized by the existence of a high cell in the north and of a low cell in the south, are encountered over the Far East and over the eastern part of the Atlantic. Thus we are under the impression that the "blocking" is accompanied by the kinetic energy transfer from the zonal motion to the ultra-long waves of wave numbers 2 and 3 .

Figure $5 \mathrm{~b}$ shows that regardless of the seasons, the waves with $n=5$ to 7 give their kinetic energy to the other waves through the nonlinear process $L(n)$. It is of great interest to find that in January and February, when the active blocking predominated, the ultra-long waves receive a great deal of kinetic energy from the other waves, because $L(n)$ is positive with large magnitude for $n=2$ and 3 .

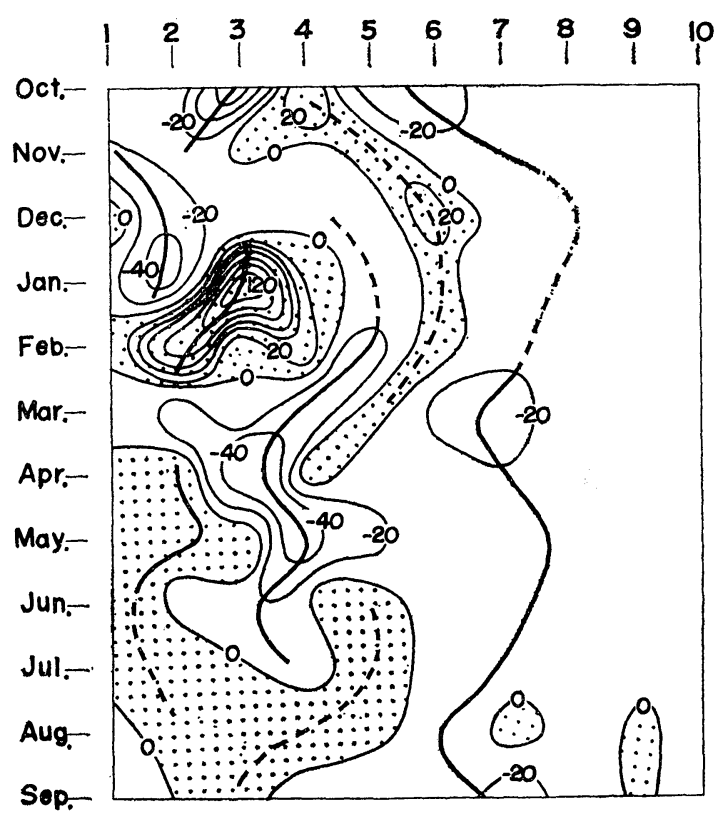

Fig. 5a. Isopleth of monthly mean value of $M(n)$ from October 1962 to September 1963 in the unit of $10^{18}$ ergs $\sec ^{-1}$.

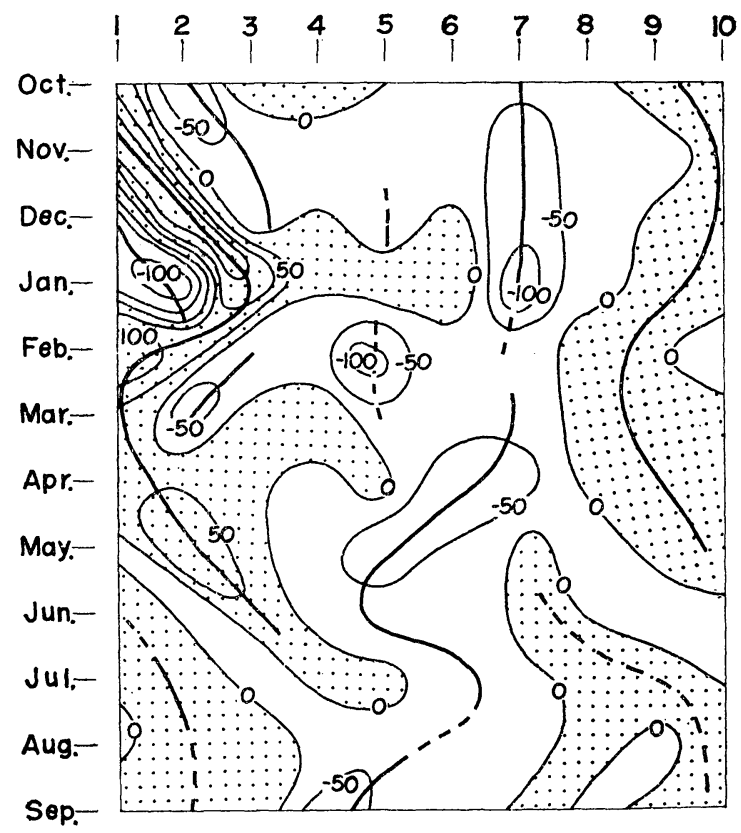

Fig. 5b. Isopleth of monthly mean value of $L(n)$. 


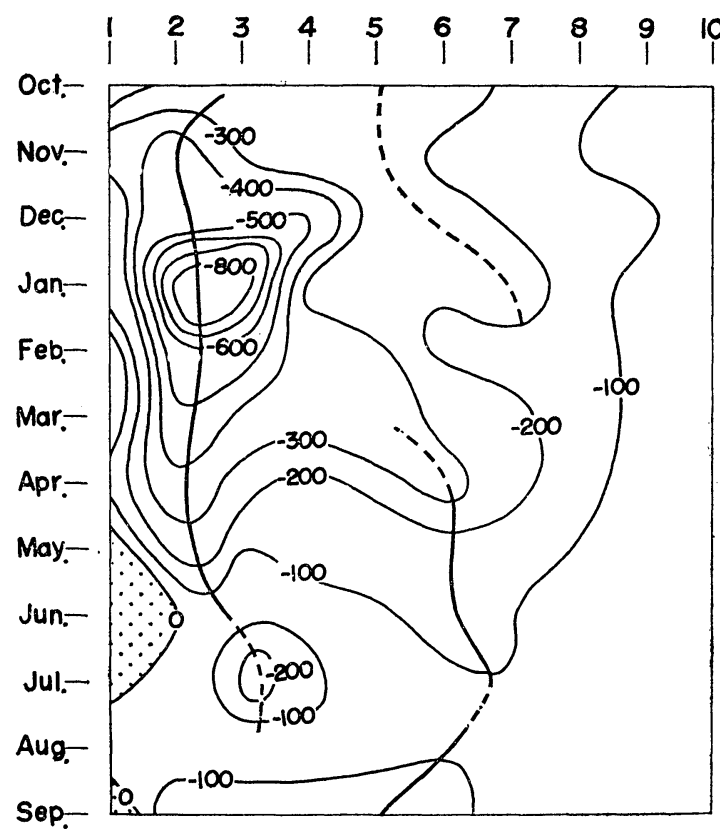

Fig. 5c. Isopleth of monthly mean value of $N(n)$.

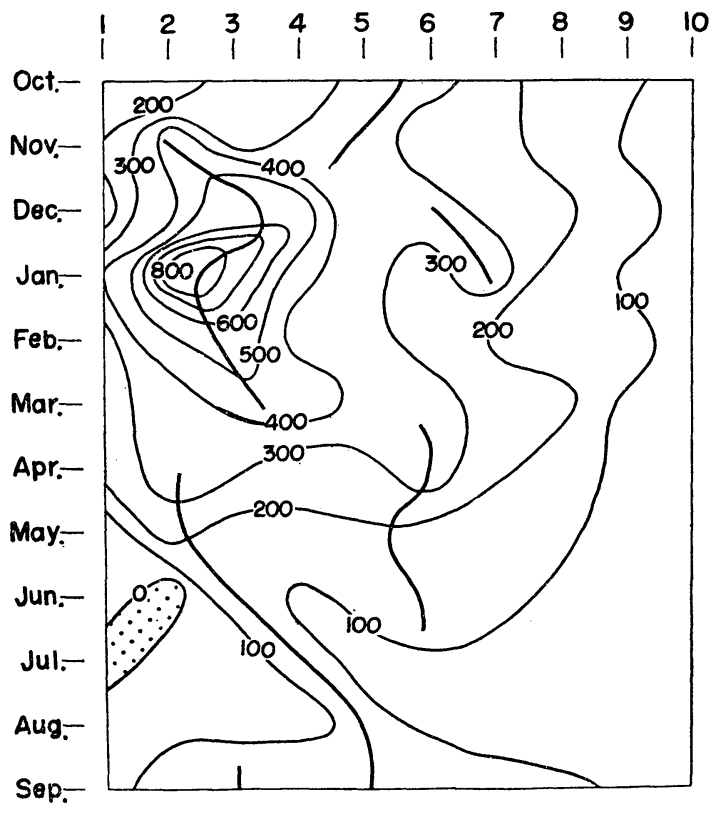

Fig. 5d. Isopleth of monthly mean value of $C(n)$.

As is seen in Fig. $5 \mathrm{c}$, showing the isopleth of $N(n)$, the very long waves of wave numbers 2 and 3 are primarily important in transferring energy to the upper atmosphere, especially in the winter. In the summer

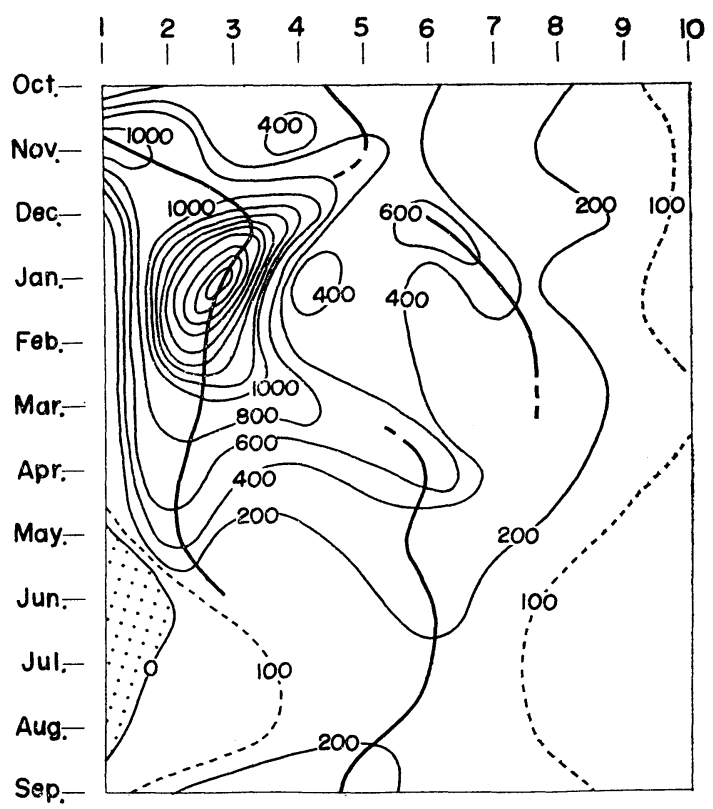

Fig. 5e. 1sopleth of monthly mean value of $S(n)$.

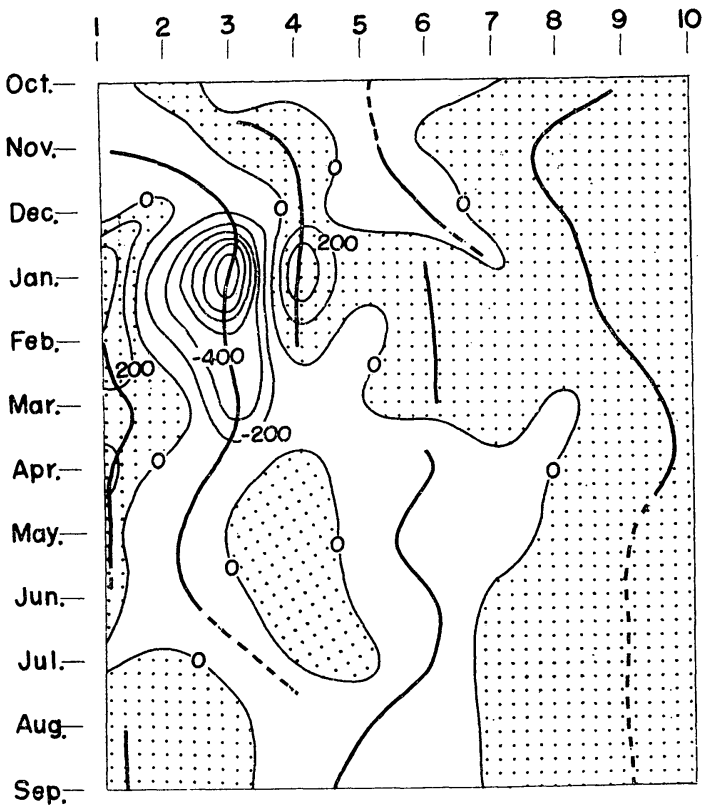

Fig. 5f. Isopleth of monthly mean value of $T(n)$.

season, however, the long waves of wave numbers 5 to 7 are as important as the very long waves for the transfer process.

An outstanding feature which appeared in the isopleth of $C(n)$ is that there is a great 


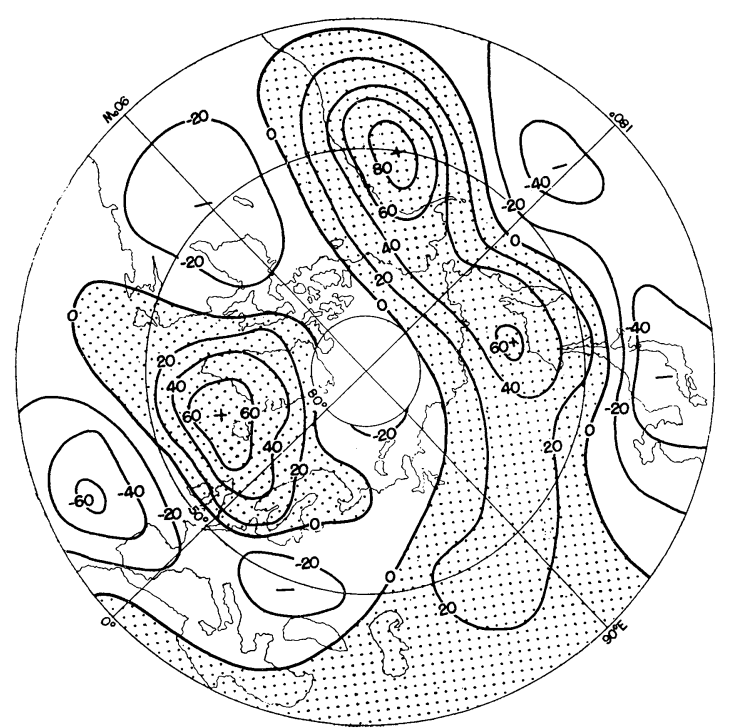

Fig. 6. Anormaly pattern of the monthly mean $500 \mathrm{mb}$ heights in January 1963 (after Y. Arai). Isolines are for $200 \mathrm{ft}$ intervals.

deal of release of potential energy into kinetic energy, for the waves with $n=2$ and 3 , in January; this would be one of the characteristic features of the blocking situation. We also note in Fig. $5 \mathrm{~d}$ that throughout the entire year $C(n)$ is somewhat large for the waves $n=5$ and 6 .

Taking a look at Fig. $5 \mathrm{e}$ which shows the isopleth of $S(n)$, we find a large transformation of available potential energy from $P(o)$ to $P(2)$ and $P(3)$. In January, this transformation is extremely large, perhaps because "blocking" is accompanied by a strong northward sensible heat transfer due to the ultralong waves of wave numbers 2 and 3. Somewhat large values of $S(n)$ can be observed for the waves of $n=5$ to 7 all the year round, presumably this is associated with the vertical tilt of the axes of the respective migratory troughs and wedges.

A glance at Fig. $5 \mathrm{f}$, showing the isopleth of $T(n)$, will reveal that in January the waves of wave numbers 2 and 3 largely furnish their potential energy to all the other waves through nonlinear interaction. This might be one of the important characteristics we encounter when active blocking persists for a long time.

We will find it interesting to present a schematic picture showing the energy budget

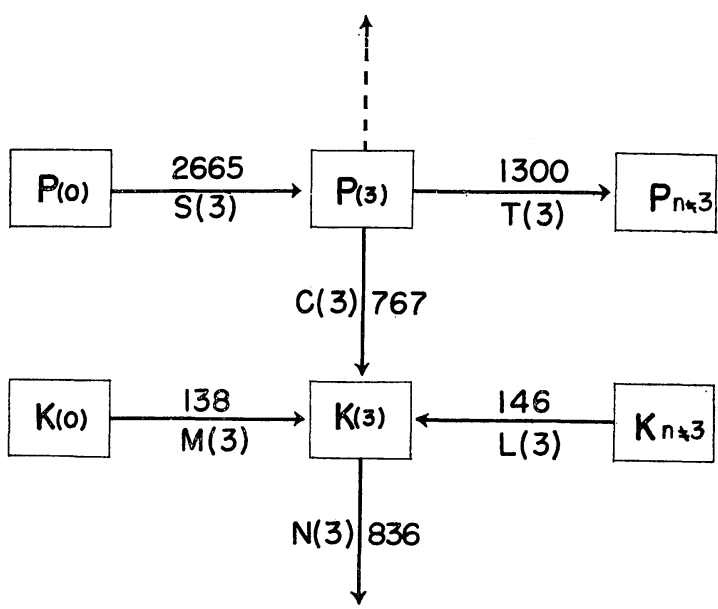

Fig. 7. Energy budget for the wave of wave number 3 in January 1963. The unit of each interaction term is $10^{18} \mathrm{ergs} \mathrm{sec}^{-1}$.

in January 1963, which would serve to expose some of the interesting aspects of the blocking phenomena. Figure 7 gives the energy cycle for the wave of wave number 3 ; this wave may be regarded as the most significant wave in the blocking pattern. A comparison between Figures 3 and 7 will show, first of all, that the transformation of available potential energy from $P(o)$ into $P(3)$ is about four times larger than that in the annual average. This probably indicates that the establishment of a large-scale temperature pattern in the blocking is accomplished at the expense of the north-south temperature contrast. The redistribution of available potential energy between the wave $n=3$ and all other waves also seen to be active in this month, amounting to about $1,300 \times 10^{18} \mathrm{ergs} \mathrm{sec}^{-1}$ which is about six times as large as the annual mean value shown in Fig. 3. Here we must emphasize that the wave of wave number 3 loses its available potential energy due to a nonlinear process $T(3)$, this direction being entirely opposite to that for the kinetic energy redistribution $L(3)$. A large transport of energy from the lower to the upper atmosphere, shown by $N(3)$, occurs in accordance with a large generation of kinetic energy due to the conversion process, represented by $C(3)$. It is our speculation in this paper that the blocking significantly contributes to transfer energy to the upper atmosphere, where the generation of kinetic energy 
due to conversion from available potential energy is not supposed to be large enough to maintain the circulation there. It may be worthwhile to note that the wave of wave number 3 receives its kinetic energy through two barotropic processes of $M(3)$ and $L(3)$, i.e., $K(3)$ is supported by the transfer of kinetic energy both from the zonal mean motion and from the other waves in this particular month when the active blocking predominated over the northern hemisphere.

The main results obtained in this section may be summarized as follows :

(1) So far as the lower atmosphere is concerned, the release of available potential energy is most active for the wave of wave number 3. This conversion process seems to be largely associated with the diabatic effect due to the land and sea distributions.

(2) The release of available potential energy is almost compensated for by energy transfer to the upper atmosphere; these two processes are primarily important in the energy cycle in the lower atmosphere. The export of energy to the upper atmosphere is largely due to the ultra-long waves of wave numbers 2 and 3 .

(3) The kinetic energy of the ultra-long waves is partly supported by the supply from all the other waves through nonlinear interaction.

(4) "Blocking" plays an important role in the energy cycle in the atmosphere ; 1 ) the transformation of available potential energy from the zonal to the eddy component becomes quite large, 2) the redistribution of available potential energy, through the nonlinear process, from the wave of wave number 3 to all the other waves becomes active, 3) a large transfer of energy to the upper atmosphere occurs in accordance with a large generation of kinetic energy in the lower atmosphere, 4) the wave with wave number 3 is in a barotropic unstable state, receiving kinetic energy from the zonal motion, 5) the wave of wave number 3 also receives a great deal of kinetic energy from the other waves through nonlinear interaction.

Referring to these results, it may not be too much to say that the ultra-long waves of wave numbers 2 and 3 seem to be as important as the long waves of wave numbers around 6 in maintaining the general circulation of the atmosphere.

\section{The spectrum}

In the preceding section we presented the isopleths of the monthly mean values of the interaction terms to see their variability with respect to time. In this section an attempt will be made to measure the spectrum of each interaction term by using the daily values. The analysis will be developed through the use of cross-correlations and Fourier trans-
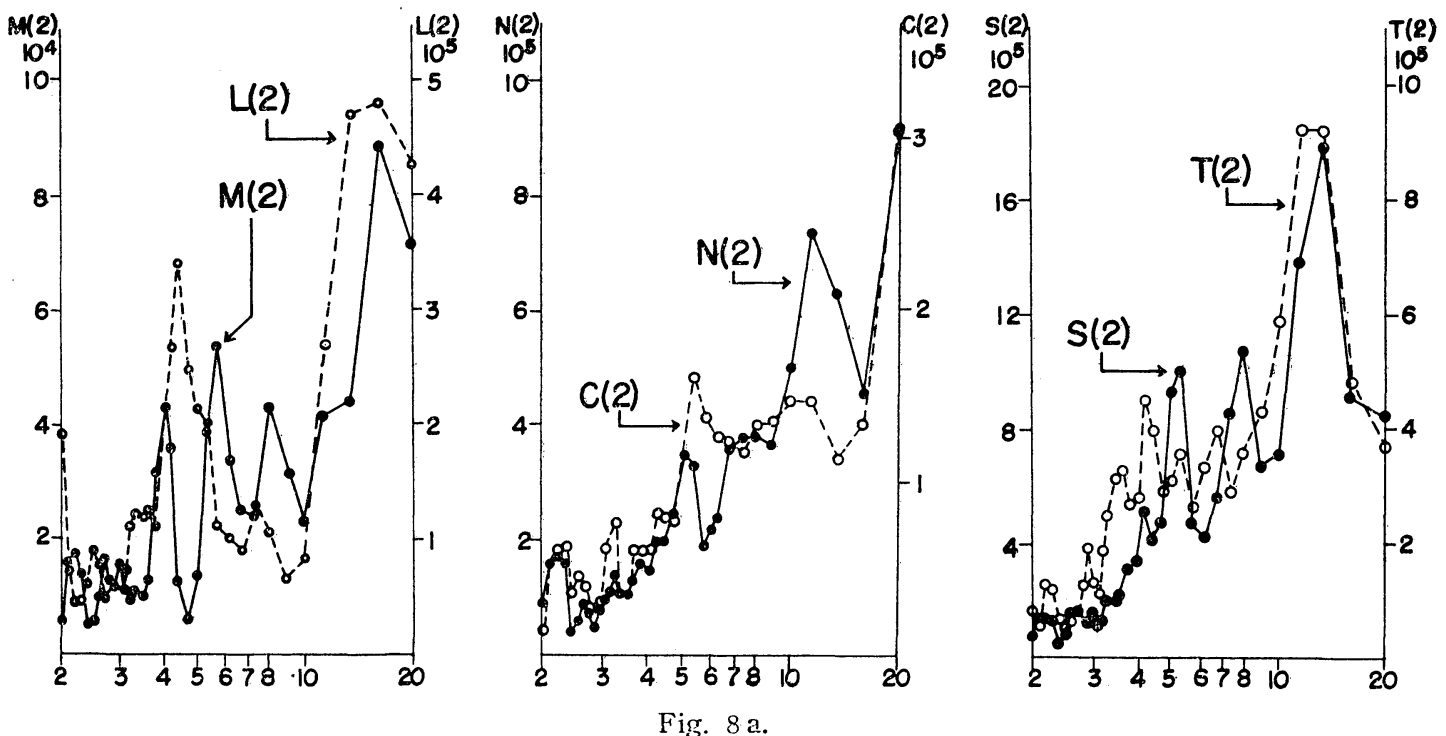

Fig. 8 a. 


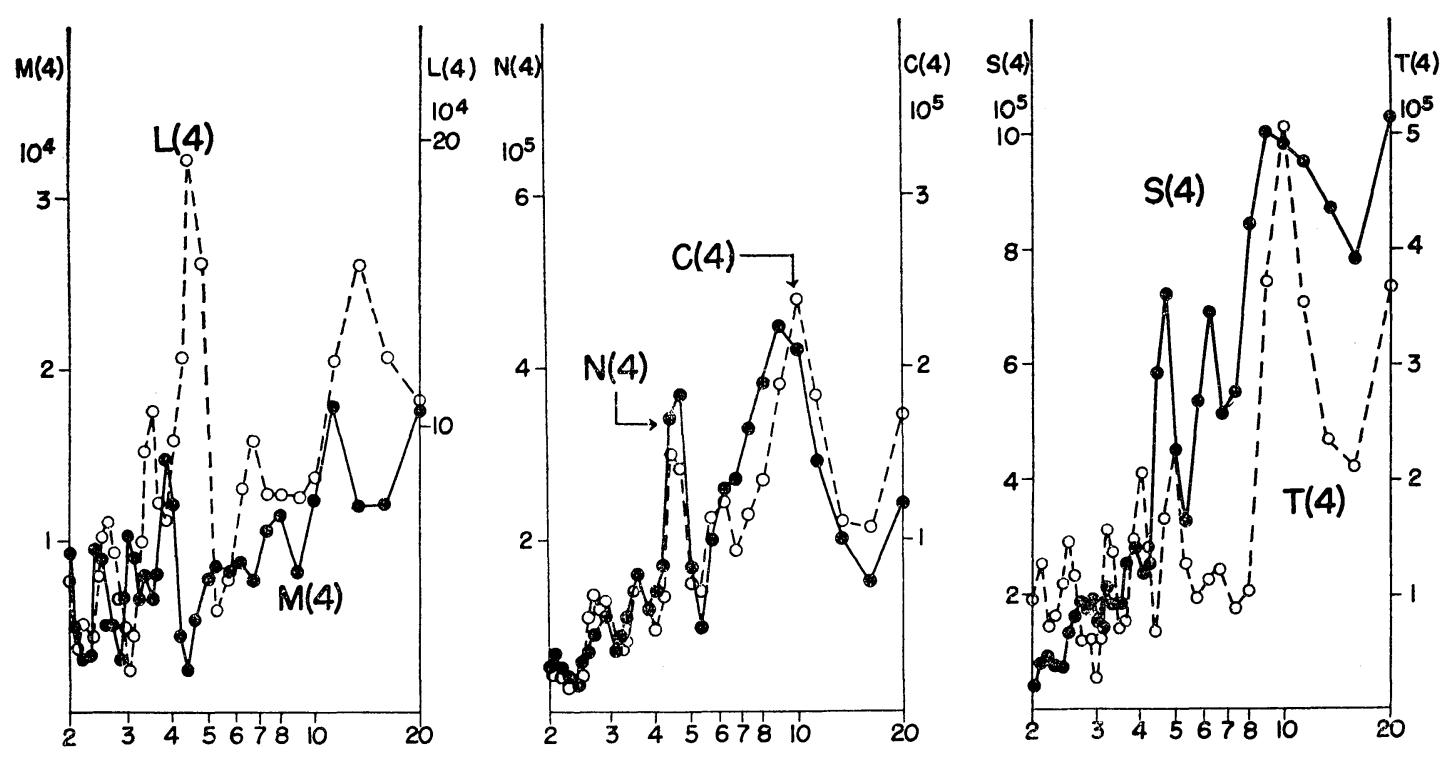

Fig. $8 \mathrm{~b}$.
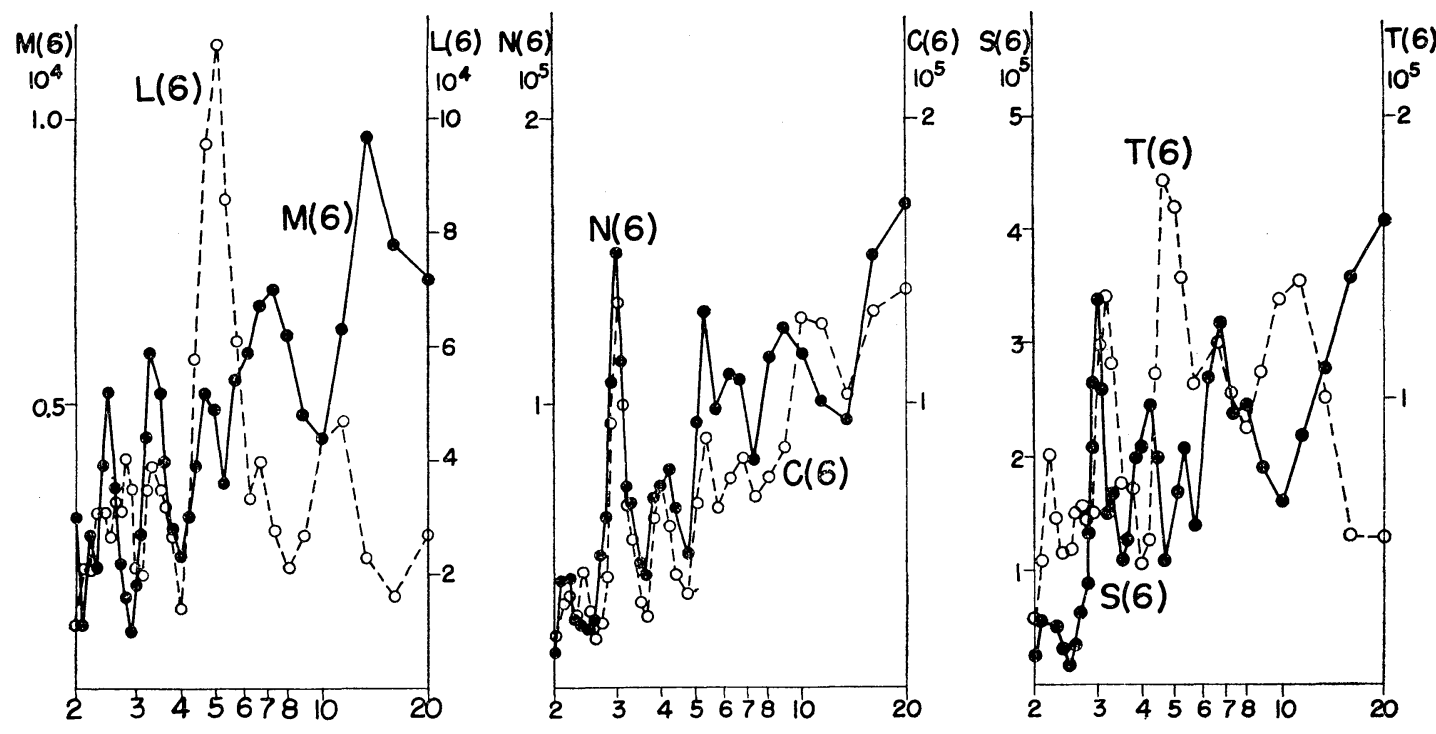

Fig. $8 \mathrm{c}$.

forms using the same method as we did in the previous paper (1964). It is our purpose to find the dominant periods of the fluctuations in the interaction terms, and hence to study the nature of the energy cycle in the atmosphere more thoroughly.

To save space, we shall only present the results obtained for the winter half-year. Figure 8 demonstrates the power spectra of various interaction terms in the winter for the respective waves $n=2,4,6,8$ and 10 .
For the waves $n=2$ and 4 , each interaction term has a pronounced peak at the periods of 10 to 13 days, with another marked peak at the period of about 5 days. With regard to the waves of wave numbers 6 and 8 , we find that (1) the spectrum is most pronounced at the period of about 5 days, (2) the fluctuations with periods of 10 to 13 days are less significant, (3) even such a short period of fluctuation as 3 days appears to be important for some of the interaction terms. Taking a 

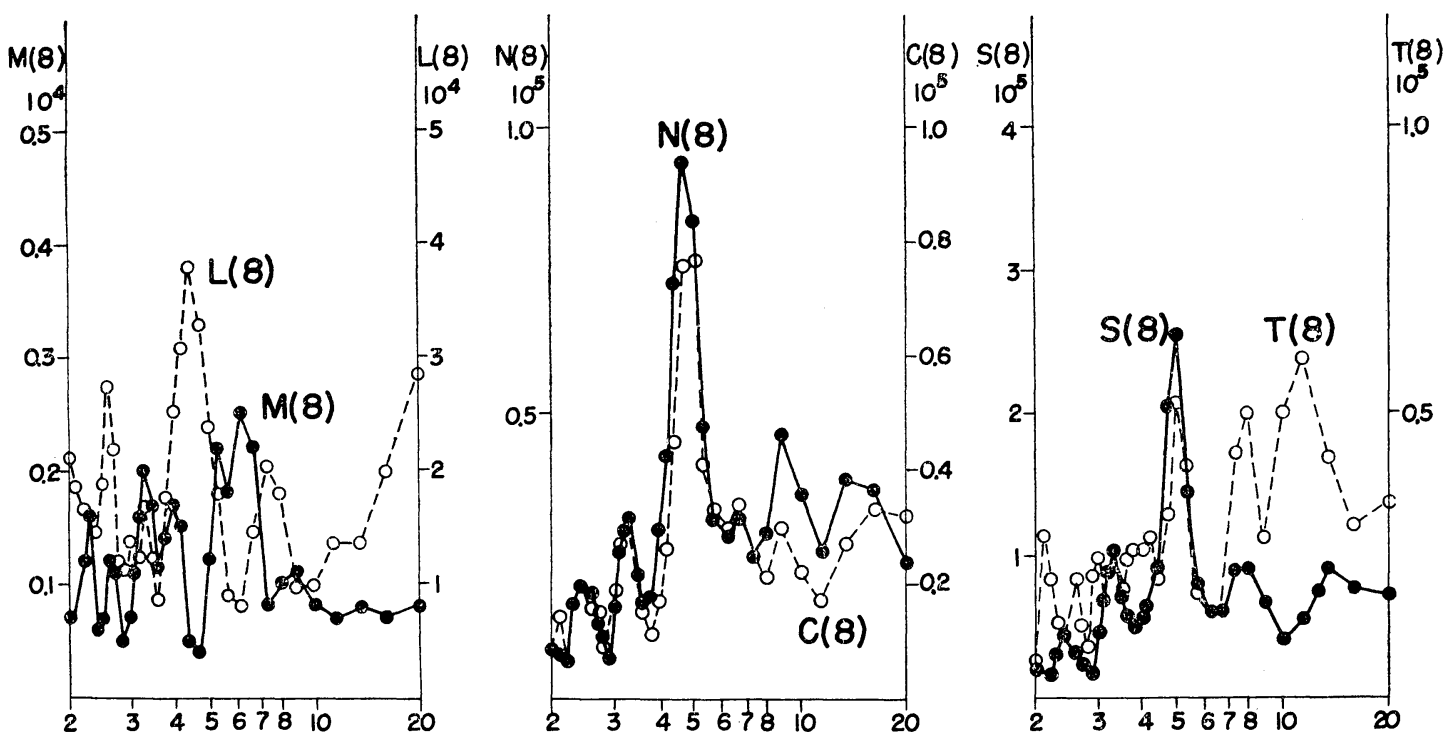

Fig. $8 \mathrm{~d}$.
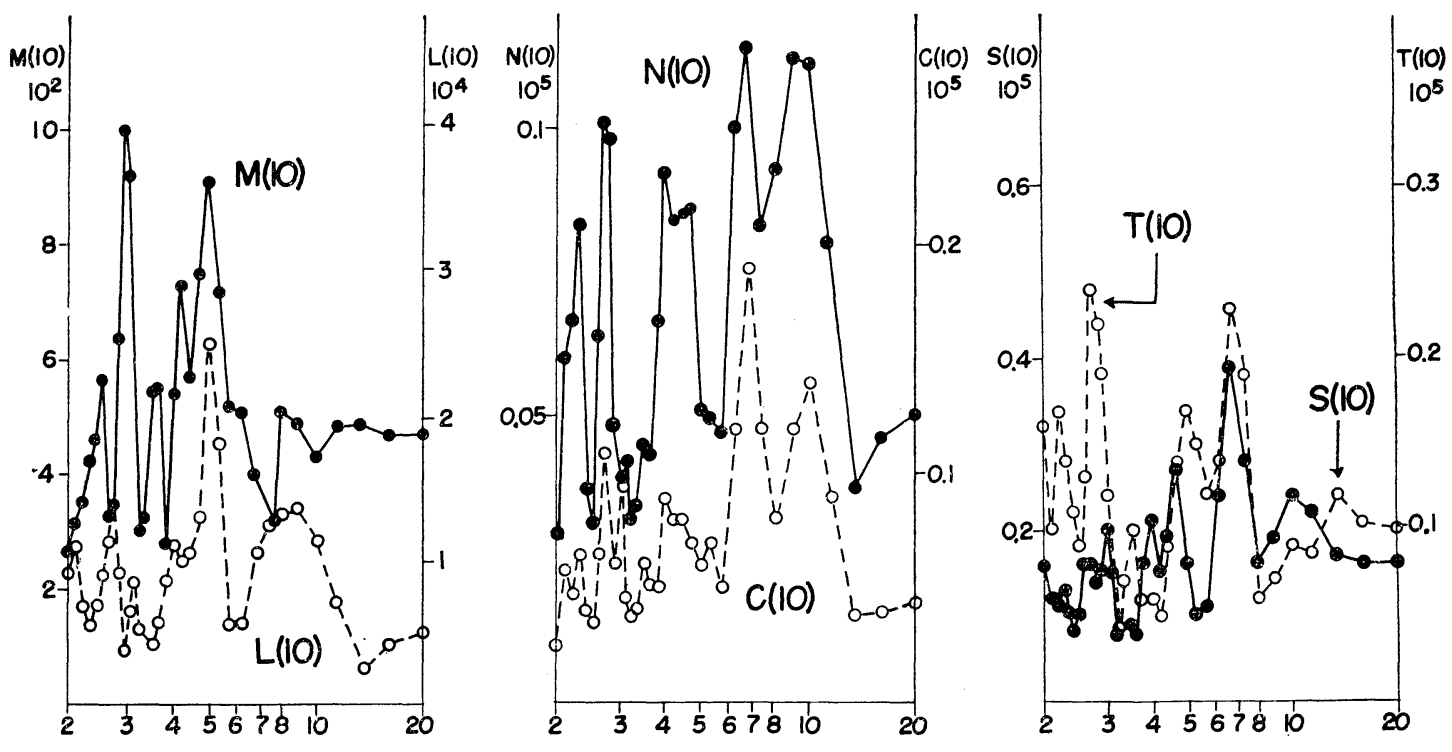

Fig. $8 \mathrm{e}$.

Fig. 8. The spectra of each interaction term in the winter half-year for the wave number 2 (a), for the wave number 4 (b), for the weve number 6 (c), for the wave number 8 (d) and for the wave number 10 (e) in the unit of $\left(10^{18} \text { ergs } \mathrm{sec}^{-1}\right)^{2}$ day, plotted against period expressed in day.

look at the spectra for the wave $n=10$, the extreme importance of the fluctuations with periods shorter than 5 days can be noticed at once, whereas the long period fluctuations longer than 10 days are observed to be less important. Here, it must be added that the magnitudes of all spectra for $n=10$ are much smaller than those we observed for $n=2$ and 4.

It is certainly not appropriate to make any definite conclusion about the nature of the fluctuations of the interaction terms from the very limited application of the spectrum analysis presented above. However, we think 
it has been established in Fig. 8 that the period in the spectrum of any interaction term tends to become shorter as the wave number increases; the periods longer than 10 days appear to be important for the longer waves $n=2$ and 4 , and the fluctuations with periods shorter than 5 days are essential for the shorter waves, such as the wave $n=10$.

Using the daily values at the $500 \mathrm{mb}$ level in the entire year 1962, the present authors (1964) found that both $M(n)$ and $L(n)$ show two distinct periods at about 10 days and at about 20 days. In the present results shown in Fig. 8, however, we cannot say much about the spectrum with the period of 20 days, because the 20-day period is the longest period considered and is not entirely reliable due to the smearing effect of the spectrum. As for the 10-day period, we also found in this study that the fluctuation of any interaction term has a marked peak around this period. In the numerical experiments made by Saltzman (1959), Baer (1961), Aihara (1963), and Mintz and Arakawa (1963), the interaction terms appear to change somewhat periodically with the period about 10 days. There seems to be no doubt that the fluctuations of the interaction terms should be accompanied with the variations of the northsouth gradient of the zonal mean temperature, the vertical shear of the zonal mean wind, the meridional transports of momentum and sensible heat, and so on. In the near future we will investigate, from observations, the nature of the fluctuations of various quantities mentioned above. It is certain that this type of investigation would serve to expose some of the interesting aspects of the general circulation in the atmosphere.

\section{Acknowledgments}

The writers are deeply grateful to Dr. B. Saltzman for the discussions kindly exchanged with one of the authors, who was at Massachusetts Institute of Technology, Cambridge, Mass., when writing this article. They wish to express their thanks to $\mathrm{Mr}$. T. Asakura and Mr. K. Kuboki, for their kindness in supplying punched cards of data. Thanks are also due to Mrs. A. Braken for reading this article and giving us valuable suggestions. The writers are indebted to Mrs. H.
Shinoda and Mr. T. Sakurai for preparing the figures presented in this article, and to Miss M.L. Guillot for typing the manuscript.

\section{References}

Aihara, M., 1963: Some characteristic features of the large-scale disturbance in a baroclinic zonal current. J. meteor. Soc. Japan, Ser. II, 41, 82107.

Baer, F., 1961: The extend numerical integration of a simple barotropic model. J. Meteor., 18, 319-339.

Charney, J. G., 1947: The dynamics of westerly current. J. Meteor., 4, 135-162.

Mintz, Y. and A. Arakawa, 1963: To be published.

Murakami, T., 1960: On the maintenance of kinetic energy of the large-scale stationary disturbances in the atmosphere. Sci. Rpt. No. 2, M.I.T. Plan. Circ. Proj., AF 19(604)-6108.

, 1963: Analysis of various large-scale disturbances and ths associated zonal mean motions in the atmosphere. Geofisica pura $e$ applicata, 54, 119-165.

, 1964: Multiple-level model for the $p$ - and $s$ - coordinates. J. meteor. Soc. Japan, Ser. II, 42, $1-13$.

- - and K. Tomatsu, 1964: The spectrum analysis of the energy interaction terms in the atmosphere. J. meteor. Soc. Japan, Ser. II, 42, 14-25.

Phillips, N.A., 1954: Energy transformations and meridional circulations associated with simple baroclinic waves in a two-level quasi-geostrophic model. Tellus, 6, 273-286.

Saltzman, B., 1957 : Equations governing the energetics of the larger scales of atmospheric turbulence in the domain of wave number. $J$. Meteor., 14, 513-523.

-, 1959: Numerical solution for an idealized barotropic flow. Final Report. General Circulation Project, M.I.T.

, and A. Fleisher, $1960 \mathrm{a}$ : Spectrum of kinetic energy transfer due to large-scale horizontal Reynolds stresses. Tellus, 12, 110-111.

$\ldots, 1960 \mathrm{~b}$ : The exchange of kinetic energy between larger scales of atmospheric motion. Tellus, 12, 374-377.

, $1960 \mathrm{c}$ : The modes of release of available potential energy in the atmosphere. J. geophys. Res., 65, 1215-1222.

Wiin-Nielsen, A., 1959: A study of energy conversion and meridional circulation for the largescale motion in the atmosphere. Mon. Wea. Rev., 87, 319-332.

, J. A. Brown and M. Drake, 1963: On atmospheric energy conversions between the zonal flow. and the eddies. Tellus, 15, 261-279. 


\section{下層大気中のエネルギー变換}

村上多喜雄, 戸松喜一

気象研究所

一ケ年間（1962年10月一1963年 9 月）の $500 \mathrm{mb}$ と $1000 \mathrm{mb}$ の等圧面高度をフーリエ分解し, 各波数間のエ ネルギー交換量の日々の值を計算した。年平均值とついてえられた結果は

（1）有効ポテンシヤルエネルギーから運動エネルギーへの転換は波数 3 がもっとも大きい。

（2）下層大気から上層大気へエネルギーが補給されている。波数 2 3 の超長波がこの補給にもっとも頁献し ている。

（3）波数 2 3 の超長波は非線型効果によって有効ポテンシャルェネルギーを他の波にあたえている。一方非 線型効果により他の波から運動エネルギーを補給されている。

（4）有効ポテンシャルエネルギーの带状成分から損乱成分への再配分は超長波がもっとも顕著である。

このようと超長波（とくに波数３）は下層大気のエネルギー变換に重要な役割をはたしている。とくに（1） の結果は Wiin-Nielsen (1959), Saltzman and Fleisher (1960c) の実測と違い, また従来の線型不安定理諭 からも期待されない。（1）や（4）の観測事実を説明する為には非断熱効果を考虑した新しい理論の展開が必 要となろう。

エネルギー变換量の時間的変動をしらべるためと月均值のイソプレット解析, 招よび変換量のスペクトル解析 を行なった。 